\title{
Effects of parental and nest site characteristics on nestling quality in the Tree Swallow (Tachycineta bicolor)
}

\begin{tabular}{|c|c|}
\hline Journal: & Canadian Journal of Zoology \\
\hline Manuscript ID & cjz-2018-0109.R1 \\
\hline Manuscript Type: & Article \\
\hline $\begin{array}{r}\text { Date Submitted by the } \\
\text { Author: }\end{array}$ & 28-Jun-2018 \\
\hline Complete List of Authors: & $\begin{array}{l}\text { Griebel, Ilsa; University Of Northern British Columbia Ecosystem Science } \\
\text { and Management, } \\
\text { Fairhurst, Graham; University of Saskatchewan, Biology } \\
\text { Marchant, Tracy; University of Saskatchewan, Biology } \\
\text { Clark, Robert; University of Saskatchewan, Biology; Environment and } \\
\text { Climate Change Canada }\end{array}$ \\
\hline $\begin{array}{r}\text { Is your manuscript invited for } \\
\text { consideration in a Special } \\
\text { Issue?: }\end{array}$ & Not applicable (regular submission) \\
\hline Keyword: & $\begin{array}{l}\text { cross-fostering, early-life environment, feather corticosterone, nestling } \\
\text { morphology, }<i>\text { Tachycineta bicolor }</ i>\text {, Tree Swallow, nest } \\
\text { microclimate }\end{array}$ \\
\hline
\end{tabular}

\section{SCHOLARONE Manuscripts}




\section{Effects of parental and nest site characteristics on nestling quality in the Tree Swallow (Tachycineta bicolor)}

Ilsa A. Griebel ${ }^{1}$, Graham D. Fairhurst ${ }^{1}$, Tracy A. Marchant ${ }^{1}$, and Robert G. Clark ${ }^{1,2}$

${ }^{1}$ Department of Biology, University of Saskatchewan, 112 Science Place, Saskatoon, SK, S7N 5E2

${ }^{2}$ Environment and Climate Change Canada, 116 Veterinary Road, Saskatoon, SK, S7N 0X4

\section{*Corresponding author and present address:}

Ilsa A. Griebel

Ecosystem Science and Management Program, University of Northern British Columbia

3333 University Way

Prince George, BC, Canada V2N 4Z9

Phone: 306-370-3721

Email: griebel@unbc.ca 


\title{
Effects of parental and nest site characteristics on nestling quality in the Tree Swallow
}

\section{(Tachycineta bicolor).}

Griebel, I.A., Fairhurst, G.D., Marchant, T.A., and Clark, R.G.

\begin{abstract}
Natal environment and parental quality can influence offspring phenotype, including physiological and morphological traits. We investigated how offspring morphology and feather corticosterone $\left(\mathrm{CORT}_{\mathrm{f}}\right.$; a physiological index of allostatic load) may be related to nest environment and parental characteristics, by cross-fostering three-day-old nestling Tree Swallows (Tachycineta bicolor (Vieillot, 1808)) between aspen (Populus tremuloides (Michx.)) and plywood nest boxes that differed in microclimate. We evaluated the relative importance of natal influences, common rearing environment, and nest box environment on nestling quality. Nestlings raised in aspen boxes tended to have lower $\mathrm{CORT}_{\mathrm{f}}$, although this result only approached significance. Nestling body mass was best predicted by biological mother's mass and random effects of natal and rearing nest identity, wing length best predicted by random effects of rearing nest, and head-bill length best predicted by random effects of natal nest. Therefore, nest microclimate was more important than maternal characteristics in predicting nestling physiology $\left(\mathrm{CORT}_{\mathrm{f}}\right)$, while nestling morphology was influenced by maternal morphology, and natal and rearing nest environment. Our study provides important information about how environmental and parental influences affect nestling phenotype, and will help future studies interpret similar morphological and physiological indices of nestling quality.

Key words: cross-fostering, early-life environment, feather corticosterone, nest microclimate, nestling morphology, pre-hatching effects, Tachycineta bicolor, Tree Swallow.
\end{abstract}




\section{Introduction}

Natal environment and parental quality influence offspring phenotype, including physiological and morphological traits. For birds, much of the variation in natal environment is determined by local weather conditions (particularly for open-cup nesting species) and nest microclimate (particularly for cavity-nesting species). For cavity-nesting birds, physical characteristics of the cavity itself (e.g., wall thickness) influence nest microclimate (Wiebe 2001; Fairhurst et al. 2012a), with important consequences for nestling morphology, behaviour, and physiology (e.g., Pérez et al. 2008; Ardia et al. 2010; Glassey et al. 2014). Besides affecting nestling phenotype, nest environment can also alter parental fitness components, such as nestling survival and fledging success (Siikamaki 1996; Ardia 2013). However, in addition to nest environment, parental quality plays an important role in determining nestling phenotype (e.g., nestling growth rate, body mass, immune response, and plumage colouration: Hipfner 1997; García-Navas and José Sanz 2011; Jacquin et al. 2012; Robinson et al. 2014). Parental quality also affects fitness traits, such as nestling survival (Voltura et al. 2002; Sasvari et al. 2004). A number of factors, like age, breeding experience, provisioning effort, plumage ornamentation, and breeding date, can indicate parental quality (e.g., Bogdanova et al. 2007; Szöllősi et al. 2009; Byholm et al. 2011; García-Navas and José Sanz 2011; Harriman et al. 2017). For example, parents of higher quality may provision at higher rates or provide larger amounts of food per feeding visit compared to parents of lower quality.

Morphological and physiological traits can be measured as proxies for nestling quality, where higher quality individuals are more likely to survive and thus, potentially have higher fitness. The hormone corticosterone (CORT) can be used as an index of allostatic load or stress in birds (Blas 2015), providing a physiological measurement of nestling quality (Criscuolo et al. 
2005; Saino et al. 2005; Angelier et al. 2009). CORT in nestlings responds both to the environment and parental care (Kitaysky et al. 2001; Blas et al. 2005, 2006; Love and Williams 2008) and is sensitive to subtle changes in energy demands (Blas 2015), making it ideal for investigating determinants of nestling quality and performance. Nestling CORT levels may vary depending on morphological, behavioural, and physiological attributes of parental quality (e.g., Harding et al. 2009; Rensel et al. 2010; Crino et al. 2011; Fairhurst et al. 2012b; Lynn and Kern 2014), and are also affected by environmental factors such as local weather conditions and nest microclimate (Lobato et al. 2008; Bize et al. 2010; Fairhurst et al. 2012a). Nestling quality also can be assessed using morphological measurements such as body mass and measures of structural size (Naef-Daenzer et al. 2001; Sankamethawee et al. 2009; Monticelli and Ramos 2012). Similar to CORT, nestling morphology can be influenced by nest microclimate (Salaberria et al. 2014) and multiple aspects of parental quality (behaviour: Stodola et al. 2010; Coe et al. 2015; morphology: Hainstock et al. 2010; physiology: Jacquin et al. 2012).

Although evidence suggests that both nest microclimate and parental quality influence nestling quality, to our knowledge no study has evaluated both of these potentially inter-related factors simultaneously to determine their relative importance. The nest site quality hypothesis, which focuses on environmental effects, asserts that nestlings from higher quality sites will be of better quality than nestlings from low-quality sites, regardless of adult quality (e.g., Hooge et al. 1999). For cavity-nesting birds, the quality of the nest site can be experimentally manipulated by using different types of nest boxes (Lambrechts et al. 2010). For example, nest boxes with thicker walls have more stable temperature conditions, resulting in nestlings spending more time in their thermal neutral zone, whereas temperature fluctuations are more pronounced in thinwalled nest boxes and so nestlings spend less time in their thermal neutral zone (e.g., Fairhurst et 
al. 2012a). Thus, nest boxes with thicker walls may represent higher quality nest sites compared to boxes with thinner walls. The individual quality hypothesis, in contrast, focuses on genetic effects and predicts that higher quality adult birds (e.g., larger, higher body condition parents) will produce higher quality young (e.g., larger, higher body condition nestlings with lower CORT levels), regardless of nest site quality (e.g., Wilson and Nussey 2010).

We used a partial cross-fostering experimental design to create broods where half of the nestling Tree Swallows (Tachycineta bicolor (Vieillot, 1808)) raised together were hatched in the nest box of rearing ("resident" nestlings), while the other half were hatched in a different nest box ("foster" nestlings). Thus, foster nestlings were expected to be (more) genetically different from the parents raising them than were resident nestlings. Cross-fostering occurred between thick-walled boxes constructed of rough-cut aspen (Populus tremuloides (Michx.)) wood and thin-walled boxes constructed of plywood. Aspen and plywood boxes have distinct microclimates (Fairhurst et al. 2012a), providing contrasting environmental conditions for nestlings. We predicted that, if pre-hatching effects were most important (e.g., maternal and genetic effects), siblings raised in different boxes would be more similar to one another with regard to body mass, structural size, and CORT levels than to foster nestlings sharing the same box. Alternatively, if common rearing environment effects are important, we expected nestlings raised in the same box would be more similar to one another with respect to these variables than to sibling nestlings raised in a different box. In addition, if nest box effects are important, we predicted that nestlings raised in aspen boxes would differ most from those raised in plywood boxes, regardless of origin. Specifically, we predicted that nestling quality would be lower, as indicated by higher CORT levels or smaller morphological measurements, in nestlings hatched and raised in plywood nest boxes (Fairhurst et al. 2012a). We predicted that nestlings with lower 
quality parents would also be lower quality (i.e., higher CORT levels or smaller morphological measurements; Harding et al. 2009; Love and Williams 2008). In our study population, nestlings with lower body mass have lower first-year survival (Harriman 2014). Although the relationship between CORT and individual quality is no doubt context dependent and need not always be negative (Bonier et al. 2009; Rivers et al. 2012; Madliger and Love 2016), our predictions are based on previous work with the same study population showing that higher levels of CORT from feathers were associated with poorer nestling quality (reduced nestling growth and fledging success; Fairhurst et al. 2013), as well as being hatched and raised in plywood boxes (Fairhurst et al. 2012a). Here, we also measured levels of CORT in nestling feathers (CORT $)$, which provides an integrated measure of CORT during feather growth (Bortolotti et al. 2008; Fairhurst et al. 2013; Hõrak et al. 2013; Jenni-Eiermann et al. 2015; for a review see Romero and Fairhurst 2016) that reflects energy management during development (Johns et al. 2018) and, thus, is a convenient way of assessing nestling quality during early life in Tree Swallows.

\section{Material and methods}

Field methods. Work was conducted at St. Denis National Research Area (SDNRA), Saskatchewan, Canada $\left(52^{\circ} \mathrm{N}, 106^{\circ} \mathrm{W}\right)$, from May to July of 2013 and 2014 . We alternated placement of aspen $(n=40)$ and plywood $(n=40)$ nest boxes to control local effects, spacing each box $30 \mathrm{~m}$ apart along grid roads and trails. Aspen and plywood nest boxes did not differ in entrance orientation, hole size or internal floor dimensions. However, aspen nest boxes had a wall thickness of $\sim 4 \mathrm{~cm}$ and retained the natural bark of the tree, while plywood boxes had a wall thickness of $1 \mathrm{~cm}$ and were painted medium-dark brown. Nest boxes were checked daily (2013) or every 2 days (2014) during nest building. When the first egg was laid, the nest was checked 
daily until we observed the same number of eggs for 3 consecutive days. We began checking the nest again near its estimated hatching date (12 days after the last egg was laid) and recorded the actual hatching date and number of young hatched. When at least all but one egg had hatched, adults were trapped, banded, and measured (length of wing chord and ninth primary flight feather [nearest $0.5 \mathrm{~mm}$ with a wing rule], combined head and bill [hereafter "head-bill"; nearest $0.01 \mathrm{~mm}$ with calipers], and mass [nearest $0.25 \mathrm{~g}$ with a spring balance]).

To choose nests for cross-fostering, pairs of aspen and plywood nest boxes were matched by hatching date to control for possible effects of environmental and individual quality that vary predictably over the breeding season (e.g., Harriman et al. 2017). At 3 days post-hatch (or 4 days when weather conditions did not permit cross-fostering at 3 days post-hatch), two (brood size less than or equal to five) or three (brood size greater than or equal to six) nestlings were matched for mass ( $\pm 1 \mathrm{~g})$ and cross-fostered between an aspen and plywood nest box pair (2013: $n=23$ pairs; 2014: $n=14$ pairs). To maintain size hierarchies within manipulated broods, the heaviest and lightest nestlings in broods were never cross-fostered. To distinguish between foster and resident nestlings, nestlings were marked with coloured, non-toxic marker on their thighs. In 2014, nestlings were also cross-fostered between the same nest box type as controls, with boxes and foster nestlings matched as above (plywood box pairs: $n=8$; aspen box pairs: $n=6$ ). At 12 days post-hatch, we banded and measured the nestlings (same as adults), and at 15 days, two or three adjacent flank feathers were taken from all nestlings. Feathers were stored in plain paper envelopes until CORT extraction. All field methods complied with the University of Saskatchewan’s Animal Research Ethics Board (protocol \#20070041). 
Corticosterone analysis. For the CORT extractions from feathers, we used the methods of Bortolotti et al. (2008), which have been used in Tree Swallows from this (Fairhurst et al. 2013) and other (Harms et al. 2010; Fairhurst et al. 2015) populations. A sub-sample of feathers $(n=88$ nestlings) was used, prioritizing samples with complete biometric information for all nestlings in matched nest boxes in a cross-fostering pair. Flank feathers were measured from the proximal calamus to the distal tip of the vane, the calamus then cut off and discarded, and the remaining feather re-measured. To ensure that CORT measurements were well within detectable limits, we measured two feathers for each individual bird (e.g., Fairhurst et al. 2015) and placed both feathers in a single glass vial (one vial/individual). All samples were randomly assigned to one of two batches and extracted without knowledge of the identity of the individual (feather), reducing the potential for extraction bias. To each vial, we added $10 \mathrm{~mL}$ of methanol (HPLC grade; Fisher Scientific, Fairlawn, New Jersey, USA). Vials were placed in a sonicating water bath at room temperature for $30 \mathrm{~min}$ and incubated overnight in a water bath at $50{ }^{\circ} \mathrm{C}$. Using vacuum filtration and a glass filtration funnel plugged with synthetic polyester fibre, we separated the methanol from feather, rinsing the vial and remnant pieces of feather with an additional $\sim 5 \mathrm{~mL}$ of methanol, which also was collected. The methanol extract was placed under a fume hood until completely evaporated, and then the dried extract residues were reconstituted in $500 \mu \mathrm{L}$ phosphate-buffered saline $(0.05 \mathrm{~mol} / \mathrm{L}, \mathrm{pH} 7.6)$ and frozen at $-20^{\circ} \mathrm{C}$ until analysis by radioimmunoassay using standard methods (Wayland et al. 2002). Using three additional feather samples spiked with a small amount (approximately 5000 counts $/ \mathrm{min}$ ) of ${ }^{3} \mathrm{H}$-corticosterone $\left({ }^{3} \mathrm{H}-\right.$ CORT), we determined the efficiency of the methanol recovery. These samples were processed the same as above. The two extraction batches had an average of $94 \%$ and $90 \%$ of the 
radioactivity recoverable from reconstituted samples and all CORT values were adjusted by these recovery efficiencies.

Reconstituted samples were analyzed in duplicate using radioimmunoassays. After combining $100 \mu \mathrm{L}$ of the extracted samples with $200 \mu \mathrm{L}$ of antiserum (Sigma Chemicals, LOT\#: 092M4784, CAT\#: C8784) and $100 \mu \mathrm{L}$ of ${ }^{3} \mathrm{H}-\mathrm{CORT}$ (PerkinElmer, NET399), we incubated the samples overnight (minimum $16 \mathrm{~h}$ ) at room temperature. To separate bound from free hormone, a dextran-coated charcoal stripping technique was used. We measured samples in five assays with a mean intra-assay coefficient of variation $( \pm$ SD) of $5.30 \pm 1.75 \%$ and an inter-assay coefficient of variation of $6.44 \%$, assessed using three aliquots (each run in duplicate) of a standard CORT solution (Sigma Chemicals) in each assay. Assays had a mean ( \pm SD) limit of detection ( $80 \%$ bound) of $17.55 \pm 5.77 \mathrm{pg}$ CORT/100 $\mu \mathrm{L}$. Data values were above this limit and we had no undetectable samples. Data are expressed as a function of feather length (pg/mm). Assays were performed at the University of Saskatchewan.

Statistical analyses. For nestlings, we performed analyses using only individuals with complete information for all nestlings in matched nest boxes in a cross-fostering pair. We fit general linear mixed effects models (PROC MIXED; SAS v. 9.4, SAS Institute Inc. Cary, North Carolina, USA) to test for differences in nestling physiology and morphology among experimental groups in the cross-fostering experiment, using $\mathrm{CORT}_{\mathrm{f}}$ and body mass, wing length, and length of headbill as separate response variables $\left(\mathrm{CORT}_{\mathrm{f}}: n=22\right.$ broods, 88 nestlings; morphological variables: $n=101$ broods, 502 nestlings). CORT $_{\mathrm{f}}$ data were log-transformed to improve normality, but were back-transformed when means are presented. Fixed effects were year, hatching date, brood size, nestling body mass at 12 days old $\left(\mathrm{CORT}_{\mathrm{f}}\right.$ model only), natal female body mass/wing 
length/head-bill (corresponding with the response variable; nestling morphology models only), foster female body mass/wing length/head-bill (corresponding with the response variable; nestling morphology models only), box type of hatching (aspen or plywood), box type of rearing (aspen or plywood), and whether or not an individual was cross-fostered. The means and standard errors for these parameters are presented in Table 1. Several interactions were also tested to confirm that 1 ) the effect of box type did not differ between years or between foster and non-foster nestlings (box type of hatching/rearing*year, box type of hatching/rearing*manipulation) and 2) the effect of female morphology did not depend on year or hatching date (female morphology*year, female morphology*hatching date). None of these interactions, however, was significant. All explanatory variables were tested for collinearity prior to analysis and no issues were found (tolerance values all $>0.2$ ). We re-ran the $\mathrm{CORT}_{\mathrm{f}}$ model with nestling body mass replaced with scaled mass index to confirm it would not alter our results. Scaled mass index, a proxy for body condition (Peig and Green 2009), was calculated using the following equation:

$$
\hat{M}_{i}=M_{i}\left[\frac{L_{0}}{L_{i}}\right]^{b_{S M A}}
$$

where $M_{i}=$ body mass, $L_{i}=$ the linear body measurement (here, length of head-bill as it was most strongly correlated with mass), $L_{0}=$ the arithmetic mean of the linear body measurement for the sample, and $b_{S M A}=$ the slope from the ordinary least square regression between mass and length of head-bill, divided by the Pearson's rho from the correlation between these two variables. The correlation and regression were both performed after the variables had been $\ln$-transformed. In some Tree Swallow populations, up to $90 \%$ of the nests contain extra-pair young (Lifjeld et al. 1993; Dunn et al. 1994), and therefore, we did not include male adult morphology in our models, as the relatedness between the attending male and the nestlings was unknown. Identities of natal 
nest and rearing nest were incorporated as random effects to account for variation due to family effects (e.g., maternal and genetic effects) and clustered data (i.e., nestlings within nest boxes share a common environment). The best random effects structure for each response variable was determined prior to model selection using likelihood ratio tests.

For model selection, we used a null hypothesis significance testing approach due to the experimental design of our study (Murtaugh 2009; Mundry 2011). To eliminate variables that did not approach significance $(P>0.10$; Dupont 2009; Montgomery et al. 2012), we used a sequential elimination procedure (removing the term with the largest $p$-value) and started by removing interaction terms before main effects. By using a threshold value of $P=0.10$, we reduced the risk of excluding important effects and a higher threshold has been recommended to permit the inclusion of variables that approach significance (Golberg and Cho 2004; Moreira et al. 2005). Variables of interest (box type of hatching and rearing) were retained in the final models regardless of significance. Marginal and conditional $R^{2}$ values were calculated for all final models following Nakagawa and Schielzeth (2013).

When female morphology was retained in the final model, we considered this support for the individual quality hypothesis, whereas when box type of hatching or rearing were retained we considered this support for the nest site quality hypothesis.

\section{Results}

Nestling physiology. The box type of rearing marginally predicted $\operatorname{CORT}_{\mathrm{f}}(P=0.076)$, whereas box type of hatching had no effect $(P=0.66$; Table 2$)$. Nestlings raised in aspen boxes tended to have lower $\mathrm{CORT}_{\mathrm{f}}$ (least squares mean $\left.[\mathrm{LSM}]=8.13, \mathrm{CI}=6.92-9.55\right)$ than nestlings raised in plywood boxes $(\mathrm{LSM}=10.00, \mathrm{CI}=8.51-11.75$; Fig. 1). No other fixed effects, including 
nestling body mass, were significant predictors of $\mathrm{CORT}_{\mathrm{f}}($ all $P>0.10)$. Replacing the explanatory variable, nestling body mass, with scaled mass index did not change these results. The random effects of the rearing nest were more influential than those of the natal nest, although random effects of rearing nest were not significant $\left(\right.$ Table $2 ; R^{2}$ (marginal) $=0.054 ; R^{2}$ $($ conditional $)=0.221)$. When the analysis was restricted to 2014 when nestlings were swapped within and between nest box types, only nest box type of rearing was influential; nestlings raised in aspen boxes tended to have lower $\mathrm{CORT}_{\mathrm{f}}$ than did nestlings from plywood boxes $(P<0.08)$. Again, no other fixed effects were significant predictors (all $P>0.10$ ).

Nestling morphology. The final model for nestling body mass retained mass of the biological mother, with heavier mothers producing significantly heavier nestlings, and brood size, with smaller broods having significantly heavier nestlings (Table 2). Neither box type of hatching $(P$ $=0.34)$ nor box type of rearing $(P=0.32)$ affected body mass (Table 2$)$. Random effects of both natal nest $(P=0.001)$ and rearing nest $(P=0.023)$ were important in predicting body mass $\left(R^{2}\right.$ $($ marginal $)=0.058 ; R^{2}($ conditional $\left.)=0.416\right)$.

The final model for nestling wing length retained manipulation effect, with cross-fostered nestlings having significantly longer wings $(\mathrm{LSM}=54.8 \mathrm{~mm}, \mathrm{CI}=54.2-55.5)$ on average than nestlings that were not cross-fostered $(\mathrm{LSM}=53.6 \mathrm{~mm}, \mathrm{CI}=52.9-54.2)$. Hatching date was positively related to wing length (Table 2$)$. Neither box type of hatching $(P=0.96)$ nor box type of rearing $(P=0.87)$ affected wing length. Random effects of the rearing nest were important $(P$ $=0.003)$, while random effects of natal nest were marginally important $\left(P=0.082 ; R^{2}\right.$ (marginal) $=0.044 ; R^{2}($ conditional $\left.)=0.374\right)$. 
The final model for length of head-bill retained manipulation effect, with cross-fostered nestlings possessing significantly longer head-bills $(\mathrm{LSM}=26.67 \mathrm{~mm}, \mathrm{CI}=26.58-26.77)$ on average than nestlings that were not cross-fostered $(\mathrm{LSM}=26.57 \mathrm{~mm}, \mathrm{CI}=26.48-26.66)$. Neither box type of hatching $(P=0.38)$ nor box type of rearing $(P=0.54)$ affected length of head-bill. Random effects of the natal nest were important $(P<0.001)$, but random effects of the rearing nest were not $\left(P=0.80 ; R^{2}(\right.$ marginal $)=0.010 ; R^{2}($ conditional $\left.)=0.257\right)$.

\section{Discussion}

Variation in nestling $\mathrm{CORT}_{\mathrm{f}}$ was related to nest box type, as predicted by the nest site quality hypothesis, although our results only approached significance. Given this effect of box type and what is known about these two box types (i.e., Fairhurst et al. 2012a), differences in microclimate were likely driving the effects on nestling $\mathrm{CORT}_{\mathrm{f}}$. In 2015, daily mean (averaging $\sim 1^{\circ} \mathrm{C}$ cooler) and maximum (averaging about $3^{\circ} \mathrm{C}$ cooler) temperatures were lower in aspen compared to plywood boxes, while the daily minimum temperature did not differ; variability in temperature was also lower in aspen boxes than plywood boxes (RGC, unpubl. data). The greater insulating properties of the aspen boxes, which produce a more stable microclimate, more closely reflects the conditions experienced in natural cavities, which have lower temperature extremes when compared to nest boxes (Maziarz et al. 2017). Furthermore, trembling aspen is a preferred cavity tree for primary cavity nesters, like the Northern Flicker (Colaptes auratus (Linnaeus, 1758); Wiebe 2001), which means when aspen trees occur on the landscape they often contain natural cavities. In our study area, trembling aspen are predominant and tree swallows use natural cavities in these trees (IAG, personal observation). 
Like our study, Fairhurst et al. (2012a) also worked at SDNRA and cross-fostered nestling Tree Swallows between aspen and plywood nest boxes. There were a few minor differences between our two studies, including one-day differences in nestling age at crossfostering and feather collection. In addition, as a control we cross-fostered nestlings between the same box types, whereas Fairhurst et al. (2012a) did not. Fairhurst et al. (2012a) found the same general trend in regards to $\mathrm{CORT}_{\mathrm{f}}$, with nestlings hatched and raised in aspen nest boxes having lower $\mathrm{CORT}_{\mathrm{f}}$ than nestlings hatched and raised in plywood nest boxes. However, in terms of the cross-fostering, Fairhurst et al. (2012a) found that the box type in which the nestling hatched was more important in predicting $\mathrm{CORT}_{\mathrm{f}}$ than the box type that the nestling was raised, whereas we found box type of rearing was more important. We do not expect the one-day difference in age at cross-fostering or feather collection to cause the discrepancies in results, but we cannot completely disregard this as a possibility. Another possible explanation for the difference in results could be annual variation in environmental conditions. For example, if conditions are poor across the study area (e.g. low food supply, unfavourable weather), then variation in rearing environment may play a larger role than natal environment in determining levels of CORT compared to when conditions are good. Ambient temperatures were slightly cooler in 2009 than in 2013 and 2014, with mean daily minimum temperature differing (mean \pm SE; 2009: $9.55 \pm$ $0.59 ; 2013: 12.28 \pm 0.58 ; 2014: 11.58 \pm 0.43)$, but maximum or mean temperatures did not differ.

In nestling Barn Swallows (Hirundo rustica (Linnaeus, 1758)), rearing environment, not genetic effects, was the most important factor explaining baseline plasma CORT levels, whereas genetic and environmental factors influenced stress-induced plasma CORT (Jenkins et al. 2014). $\mathrm{CORT}_{\mathrm{f}}$ can reflect both baseline and stress-induced levels of plasma CORT, but correlations 
between feather and plasma levels of CORT may not be observed if elevations in the latter occur over a brief period of time and/or increase only slightly (Fairhurst et al. 2013). According to our study, nestling $\mathrm{CORT}_{\mathrm{f}}$ was influenced more by the rearing environment and thus, agrees with Jenkins et al.'s (2014) baseline plasma CORT results. In contrast, Fairhurst et al. (2012a) demonstrated a stronger effect of natal nest on $\mathrm{CORT}_{\mathrm{f}}$, potentially suggesting nestlings experienced stress-induced levels of CORT more frequently during the period of feather growth and thus, genetic or pre-hatching maternal effects would have been more influential (Jenkins et al. 2014). Stress-induced levels of CORT occur in response to unpredictable events, like attacks from predators or conspecifics, periods of poor weather conditions, or parasitic infestations (Landys et al. 2006). Nestling tree swallows are parasitized by a number of nest-dwelling, bloodfeeding ectoparasites, such as larval blow flies, fleas, and mites (e.g., Shutler et al. 2004), and also are negatively affected by inclement weather, which reduces the availability of flying insects, the food source of tree swallows (Winkler et al. 2013). Both of these factors may have differed in frequency and intensity among years and could possibly explain the different results found between our study and Fairhurst et al. (2012a). It was beyond the scope of our study to determine how our cross-fostering manipulation may have influenced the development of the hypothalamic-pituitary-adrenal (HPA) axis. However, given the importance of events during the pre- and post-natal periods to the development of the avian HPA axis (e.g., Love et al. 2013; Spencer et al. 2009), future studies would benefit from better understanding the relationships among maternal effects (genetics, physiology, behaviour), environmental conditions throughout the breeding period, and individual variation in CORT physiology that ultimately determine $\mathrm{CORT}_{\mathrm{f}}$ values (Romero and Fairhurst 2016). 
In terms of comparing the aspen and plywood nest boxes, we have demonstrated a potential physiological benefit (lower $\mathrm{CORT}_{\mathrm{f}}$ ), presumably through energetic savings, for nestlings raised in aspen boxes, but there could be others. For example, CORT levels in nestlings are positively associated with begging frequency (Kitaysky et al. 2001). Thus, nestlings in aspen boxes may beg, which is a costly behaviour (Trivers 1974; Godfray 1991, 1995a, b), less frequently than nestlings in plywood boxes and therefore, have more energy to invest into growth and development. Ectoparasite load and its interaction with the microclimate and chemical environment of the cavity (Lambrechts et al. 2010) could differ between aspen and plywood boxes. Nest site selection may also play a role if higher quality adults preferentially selected aspen nest boxes. Further research is needed to investigate additional benefits of a less variable nest microclimate and the effect of nest boxes in general (see Lambrechts et al. 2010).

Both the natal and rearing environment were important in determining nestling morphology, although the relative importance varied amongst specific traits. We found that random effects of natal nest were most important for body mass and length of head-bill, suggesting these morphological traits were likely more influenced by pre-hatching factors, such as genetics (Wiggins 1990), maternal transfer of hormones (Schwabl 1996; Ros 1999; Saino et al. 2005), or female incubation behavior (Coe et al. 2015). Female incubation behavior affects egg temperature, which in turn can affect nestling morphology (Nord and Nilsson 2011). Furthermore, the biological mother's body mass significantly influenced nestling body mass, supporting the individual quality hypothesis. The genetic contribution of the female (and the male) may have played a major role in determining the body mass of offspring (as supported by heritability studies: Kunz and Ekman 2000; Merila et al. 2001; Husby et al. 2011), and possibly length of head-bill. However, few studies measure head-bill, making comparisons difficult. In 
Tree Swallows, an egg cross-fostering experiment showed that mass (measured at day 16 once mass recession has begun, whereas we measured mass at day 12 before mass recession typically begins) and wing length were not heritable, but tarsus, a measure of skeletal size like head-bill, was heritable (Wiggins 1989, 1990).

Although pre-hatching effects appeared to be contributing to body mass, rearing environment was also influential in determining this trait, as well as wing length (Merila et al. 2001; Visser et al. 2006; Husby et al. 2011). This suggests that these morphological traits may be more plastic, in that they can be altered substantially by post-hatching conditions. The amount of food a nestling receives will affect its body mass and can be altered by the parent's behaviour (e.g., provisioning rate and food allocation amongst nestlings; Krebs et al. 1999; Stodola et al. 2010), the competitive ability of the nestlings (e.g. begging behaviour; Nilsson and Svensson 1996), and the environment (e.g. insect abundance, weather conditions and the microclimate of the nest site; Howe et al. 1996; Salaberria et al. 2014; Sicurella et al. 2015). Nestling wing length also can be affected by similar factors (e.g., Musgrove and Wiebe 2014; Salaberria et al. 2014). The importance of the rearing environment, but marginal influence of the natal environment, in determining wing length may reflect that this measurement includes the feather growth at the end of the wing (i.e., primary flight feathers), which may be more plastic and depend on rearing conditions, and also the structural part of the wing (i.e., bone), which may be more genetically fixed. For example, a cross-fostering experiment on House Sparrows (Passer domesticus (Linnaeus, 1758)) found a lack of origin-related variation for feather development, but a greater amount of variation arising from environmental sources (Kinnard and Westneat 2009).

Final models for lengths of head-bill and wing both retained the manipulation effect, with foster nestlings tending to be larger for both variables than nestlings that were not fostered. 
These results may be a product of the 'runt effect'. When we cross-fostered the nestlings, the largest and smallest nestling from a nest were never cross-fostered. Thus, the smallest nestling of each nest (i.e., the 'runt') always remained in its natal nest as a non-foster nestling. Therefore, all the runt nestlings accumulated in the non-fostered group, potentially producing the significant difference in size between foster and non-foster nestlings. In tree swallows broods, often the largest nestling does not typically differ much morphologically from the second or third largest nestling within a brood, whereas the smallest nestling can often be much smaller than its nest mates. Thus, the accumulation of the largest nestling in the non-foster group may not influence the mean very strongly, whereas the accumulation of the smallest nestlings in the non-foster group may be more influential and lower the mean. However, while the foster nestlings were on average less variable than non-foster nestlings (head-bill: $F_{1,100}=1.394$; wing length: $F_{1,100}=$ 1.749), neither $F$-test was significant $(P>0.10)$. Interestingly, the manipulation effect did not remain in our final model for nestling body mass. The runt effect may only have been apparent with head-bill and wing length, but not body mass, if body mass at 3 days post-hatch (the age at which nestlings were cross-fostered) effectively predicts head-bill and wing length (skeletal measurements) at 12 days post-hatch, but not body mass at 12 days post-hatch. Light-weight nestlings at 3 days post-hatch (i.e., runts) likely have short wing and head-bill lengths at 12 days post-hatch, but may not necessarily be light-weight at that time, depending on such factors as food source, selective feeding by the parents, and the timing of our measurements relative to feeding. This agrees partially with our results as we found that body mass was influenced by the rearing environment, suggesting it may be a more plastic trait, whereas head-bill was influenced by the natal environment, suggesting it may be more fixed. However, wing length was more 
influenced by rearing environment, and thus, we may have expected it to be more plastic and not show the runt effect.

In summary, we have demonstrated that both the type of nest box (implying an effect of microclimate) in which nestlings are raised and parental quality influenced nestling phenotype. We found that nestling physiology (i.e., $\mathrm{CORT}_{\mathrm{f}}$ ) was more strongly predicted by nest box type, while morphology was more influenced by parent morphology, and natal and rearing nest environment. Thus, the responses we examined could not all be explained the same way. Rather, the dominant factors explaining the variation in each trait depended on environmental context. By identifying whether pre- or post-hatching factors were most important in predicting certain aspects of nestling phenotype, our results will help future studies interpret similar morphological and physiological indices of nestling quality. Future research should examine factors that can cause annual differences in CORT levels, determine how unpredictable perturbations (e.g., harsh weather, parasitism) affect nestling CORT on an individual level, and how this may relate to metrics of fitness, such as fledging success and subsequent survival.

\section{Acknowledgements}

We are grateful to the summer staff and volunteers who assisted with collecting and entering data. We thank S. Cabezas for performing the $\mathrm{CORT}_{\mathrm{f}}$ radioimmunoassays and R.D. Dawson for providing helpful suggestions and comments on the manuscript. Funding was provided by Environment and Climate Change Canada (R.G.C.), Natural Sciences and Engineering Research Council of Canada (I.A.G., R.G.C.), and the University of Saskatchewan (G.D.F., T.A.M.). We appreciate the constructive comments from two anonymous reviewers. 


\section{References}

Angelier, F., Clement-Chastel, C., Welcker, J., Gabrielsen, G.W., and Chastel, O. 2009. How does corticosterone affect parental behaviour and reproductive success? A study of prolactin in black-legged kittiwakes. Funct. Ecol. 23(4): 784-793. doi:10.1111/j.13652435.2009.01545.x.

Ardia, D.R., Pérez, J.H., and Clotfelter, E.D. 2010. Experimental cooling during incubation leads to reduced innate immunity and body condition in nestling tree swallows. Proc. R. Soc. Lond. B Biol. Sci. 366(1689): 1881-1888. doi:10.1098/rspb.2009.2138.

Ardia, D.R. 2013. The effects of nestbox thermal environment on fledging success and haematocrit in tree swallows. Avian Biol. Res. 6(2): 99-103. doi:10.3184/175815513X13609528031394.

Bize, P., Stocker, A., Jenni-Eiermann, S., Gasparini, J., and Roulin, A. 2010. Sudden weather deterioration but not brood size affects baseline corticosterone levels in nestling Alpine swifts. Horm. Behav. 58(4): 591-598. doi:10.1016/j.yhbeh.2010.06.020.

Blas, J., Baos, R., Bortolotti, G.R., Marchant, T., and Hiraldo, F. 2005. A multi-tier approach to identifying environmental stress in altricial nestling birds. Funct. Ecol. 19(2):315-322.

Blas, J., Baos, R., Bortolotti, G.R., Marchant, T., and Hiraldo, F. 2006. Age-related variation in the adrenocortical response to stress in nestling white storks (Ciconia ciconia) supports the developmental hypothesis. Gen. Comp. Endocrinol. 148(2):172-180. 
Blas, J. 2015. Stress in birds. In Sturkie's avian physiology, 6th edition. Edited by C. Scanes. Academic Press-Elsevier, San Diego. pp. 769-810.

Bogdanova, M.I., Nager, R.G., and Monaghan, P. 2007. Age of the incubating parents affects nestling survival: an experimental study of the herring gull Larus argentatus. J. Avian Biol. 38(1): 83-93. doi:10.1111/j.2007.0908-8857.03701.x.

Bonier, F., Martin, P.R., Moore, I.T., and Wingfield, J.C. 2009. Do baseline glucocorticoids predict fitness? Trends Ecol. Evol. 24(11): 634-642.

Bortolotti, G.R., Marchant, T.A., Blas, J., and German, T. 2008. Corticosterone in feathers is a long-term, integrated measure of avian stress physiology. Funct. Ecol. 22(3): 494-500. doi:10.1111/j.1365-2435.2008.01387.x.

Byholm, P., Rousi, H., and Sole, I. 2011. Parental care in nesting hawks: breeding experience and food availability influence the outcome. Behav. Ecol. 22(3): 609-615. doi:https://doi.org/10.1093/beheco/arr019.

Coe, B.H., Beck, M.L., Chin, S.Y., Jachowski, C.M.B., and Hopkins, W.A. 2015. Local variation in weather conditions influences incubation behavior and temperature in a passerine bird. J. Avian Biol. 46(4): 1-10. doi: 10.1111/jav.00581.x.

Crino, O.L., Van Oorschot, B.K., Johnson, E.E., Malisch, J.L., and Breuner, C.W. 2011. Proximity to a high traffic road: Glucocorticoid and life history consequences for nestling white-crowned sparrows. Gen. Comp. Endocrinol. 173(2): 323-332. doi:http://dx.doi.org/10.1016/j.ygcen.2011.06.001. 
Criscuolo, F., Chastel, O., Bertile, F., Gabrielsen, G.W., Le Maho, Y., and Raclot, T. 2005.

Corticosterone alone does not trigger a short term behavioural shift in incubating female common eiders Somateria mollissima, but does modify long term reproductive success. J. Avian Biol. 36(4): 306-312. doi:10.1111/j.0908-8857.2005.03371.x

Dunn, P.O., Robertson, R.J., Michaud-Freeman, D., and Boag, P.T. 1994. Extra-pair paternity in tree swallows: why do females mate with more than one male? Behav. Ecol. Sociobiol. 35(4): 273-281.

Dupont, W.D. 2009. Statistical modeling for biomedical researchers: a simple introduction to the analysis of complex data. Cambridge University Press, Cambridge, U.K.

Fairhurst, G.D., Treen, G.D., Clark, R.G., and Bortolotti, G.R. $2012 a$. Nestling corticosterone response to microclimate in an altricial bird. Can. J. Zool. 90(12): 1422-1430. doi:10.1139/cjz-2012-0096.

Fairhurst, G.D., Navarro, J., González-Solís , J., Marchant, T.A., and Bortolotti, G.R. $2012 b$. Feather corticosterone of a nestling seabird reveals consequences of sex-specific parental investment. Proc. R. Soc. Lond. B Biol. Sci. 279(1726): 177-184.

Fairhurst, G.D., Marchant, T.A., Soos, C., Machin, K.L., and Clark, R.G. 2013. Experimental relationships between levels of corticosterone in plasma and feathers in a free-living bird. J. Exp. Biol. 216(21): 4071-4081. doi:10.1242/jeb.091280.

Fairhurst, G.D., Berzins, L.L., Bradley, D.W., Laughlin, A.J., Romano, A., Romano, M., Scandolara, C., Ambrosini, R., Dawson, R.D., Dunn, P.O., Hobson, K.A., Liechti, F., 
Marchant, T.A., Norris, D.R., Rubolini, D., Saino, N., Taylor, C.M., Whittingham, L.A., and Clark, R.G. 2015. Assessing costs of carrying geolocators using feather corticosterone in two species of aerial insectivore. R. Soc. Open Sci. 2(5): 150004. doi:10.1098/rsos. 150004 .

García-Navas, V., and José Sanz, J. 2011. Seasonal decline in provisioning effort and nestling mass of blue tits Cyanistes caeruleus: experimental support for the parent quality hypothesis. Ibis, 153(1): 59-69. doi:10.1111/j.1474-919X.2010.01077.x.

Glassey, B., Gunson, M., and Muir, R. 2014. Context-dependent costs and constraints of begging and non-begging activity by common grackle nestlings at the scale of the nanoclimate. Funct. Ecol. 28(4): 904-912. doi: 10.1111/1365-2435.12225.

Godfray, H.C.J. 1991. Signalling of need by offspring to their parents. Nature, 352: 328-330.

Godfray, H.C.J. 1995a. Evolutionary theory of parent-offspring conflict. Nature, 376: 133-138.

Godfray, H.C.J. 1995b. Signaling of need between parents and young: parent-offspring conflict and sibling rivalry. Am. Nat. 146(1): 1-24.

Golberg, M.A., and Cho, H.A. 2004. Introduction to regression analysis. WIT Press, Billerica, M.A.

Hainstock, M.H., Smith, M.C., Carr, J., and Shutler, D. 2010. Parental investment and brood value in tree swallows, Tachycineta bicolor. Behaviour, 147(4): 441-464. doi:10.1163/000579509X1258007067. 
Harding, A.M.A., Kitaysky, A.S., Hall, M.E., Welcker, J., Karnovsky, N.J., Talbot, S.L., Hamer, K.C., and Gremillet, D. 2009. Flexibility in the parental effort of an Arctic-breeding seabird. Funct. Ecol. 23(2): 348-358. doi:10.1111/j.1365-2435.2008.01488.x.

Harms, N.J., Fairhurst, G.D., Bortolotti, G.R., and Smits, J.E.G. 2010. Variation in immune function, body condition, and feather corticosterone in nestling Tree Swallows (Tachycineta bicolor) on reclaimed wetlands in the Athabasca oil sands, Alberta, Canada. Environ. Pollut. 158(3): 841-848. doi:10.1016/j.envpol.2009.09.025.

Harriman, V.B. 2014. Seasonal variation in quality and survival of nestling tree swallows (Tachycineta bicolor): tests of alternate hypotheses. Ph.D. Thesis, University of Saskatchewan, 143 pages.

Harriman, V.B., Dawson, R.D., Bortolotti, L.E., and Clark, R.G. 2017. Seasonal patterns in reproductive success of temperate-breeding birds: experimental tests of the date and quality hypotheses. Ecol. Evol. 7(7): 2122-2132. doi:10.1002/ece3.2815.

Hipfner, J.M. 1997. The effects of parental quality and timing of breeding on the growth of nestling thick-billed murres. Condor, 99(2): 353-360. doi:10.2307/1369941.

Hooge, P.N., Stanback, M.T., and Koenig, W.D. 1999. Nest-site selection in the acorn woodpecker. Auk, 116(1): 45-54.

Hõrak, P., Männiste, M., Meitern, R., Sild, E., Saks, L., and Sepp, T. 2013. Dexamethasone inhibits corticosterone deposition in feathers of greenfinches. Gen. Comp. Endocrinol. 191: 210-214. doi:http://dx.doi.org/10.1016/j.ygcen.2011.06.001. 
Howe, F., Knight, R., McEwen, L., and George, T. 1996. Direct and indirect effects of insecticide applications on growth and survival of nestling passerines. Ecol. Appl. 6(4): 1314-1324. doi:10.2307/2269609.

Husby, A., Hille, S.M., and Visser, M.E. 2011. Testing mechanisms of Bergmann's rule: Phenotypic decline but no genetic change in body size in three passerine bird populations. Am. Nat. 178(2): 202-213. doi:10.1086/660834.

Jacquin, L., Blottiere, L., Haussy, C., Perret, S., and Gasparini, J. 2012. Prenatal and postnatal parental effects on immunity and growth in 'lactating' pigeons. Funct. Ecol. 26(4): 866875. doi:10.1111/j.1365-2435.2012.01988.x.

Jenkins, B.R., Vitousek, M.N., Hubbard, J.K., and Safran, R.J. 2014. An experimental analysis of the heritability of variation in glucocorticoid concentrations in a wild avian population. Proc. R. Soc. Lond. B Biol. Sci. 281(1790): 1-8. doi: 10.1098/rspb.2014.1302.

Jenni-Eiermann, S., Helfenstein, F., Vallat, A., Glauser, G., and Jenni, L. 2015. Corticosterone: effects on feather quality and deposition into feathers. Methods Ecol. Evol. 6(2): 237246. doi:10.1111/2041-210X.12314.

Johns, D.W., Marchant, T.A., Fairhurst, G.D., Speakman, J.R., and Clark, R.G. 2018. Biomarker of burden: Feather corticosterone reflects energetic expenditure and allostatic overload in captive waterfowl. Funct. Ecol. 32(2): 345-357. 
Kinnard, T.B., and Westneat, D.F. 2009. Phenotypic and genetic variance of house sparrows (Passer domesticus) early in development. Auk, 126(4): 884-895. doi:10.1525/auk.2009.08119.

Kitaysky, A.S., Wingfield, J.C., and Piatt, J.F. 2001. Corticosterone facilitates begging and affects resource allocation in the black-legged kittiwake. Behav. Ecol. 12(5): 619-625. doi:https://doi.org/10.1093/beheco/12.5.619.

Krebs, E., Cunningham, R., and Donnelly, C. 1999. Complex patterns of food allocation in asynchronously hatching broods of crimson rosellas. Anim. Behav. 57(4): 753-763. doi:anbe.1998.1029.

Kunz, C., and Ekman, J. 2000. Genetic and environmental components of growth in nestling blue tits (Parus caeruleus). J. Evol. Biol. 13(2): 199-212. doi:10.1046/j.14209101.2000.00158.x.

Lambrechts, M.M., Adriaensen, F., Ardia, D.R., Artemyev, A.V., Atienzar, F., Banbura, J., Barba, E., Bouvier, J.C., Camprodon, J., Cooper, C.B., Dawson, R.D., Eens, M., Eeva, T., Faivre, B., Garamszegi, L.Z., Goodenough, A.E., Gosler, A.G., Gregoire, A., Griffith, S.C., Gustafsson, L., Johnson, L.S., Kania, W., Keiss, O., Llambias, P.E., Mainwaring, M.C., Mand, R., Massa, B., Mazgajski, T.D., Møller, A.P., Moreno, J., Naef-Daenzer, B., Nilsson, J.A., Norte, A.C., Orell, M., Otter, K.A., Park, C.R., Perrins, C.M., Pinowski, J., Porkert, J., Potti, J., Remes, V., Richner, H., Rytkonen, S., Shiao, M.T., Silverin, B., Slagsvold, T., Smith, H.G., Sorace, A., Stenning, M.J., Stewart, I., Thompson, C.F., Tryjanowski, P., Torok, J., van Noordwijk, A.J., Winkler, D.W., and Ziane, N. 2010. The 
design of artificial nestboxes for the study of secondary hole-nesting birds: a review of methodological inconsistencies and potential biases. Acta Ornithologica, 45(1): 1-26.

Landys, M.M., Ramenofsky, M., and Wingfield, J.C. 2006. Actions of glucocorticoids at a seasonal baseline as compared to stress-related levels in the regulation of periodic life processes. Gen. Comp. Endocrinol. 148(2): 132-149.

Lifjeld, J.T., Dunn, P.O., Robertson, R.J., and Boag, P.T. 1993. Extra-pair paternity in monogamous tree swallows. Anim. Behav. 45(2): 213-229. doi:https://doi.org/10.1006/anbe.1993.1028

Lobato, E., Merino, S., Moreno, J., Morales, J., Tomas, G., Martinez-de la Puente, J., Osorno, J.L., Kuchar, A., and Mostl, E. 2008. Corticosterone metabolites in blue tit and pied flycatcher droppings: Effects of brood size, ectoparasites and temperature. Horm. Behav. 53(1): 295-305. doi:10.1016/j.yhbeh.2007.10.010.

Love, O.P., and Williams, T.D. 2008. Plasticity in the adrenocortical response of a free-living vertebrate: The role of pre- and post-natal developmental stress. Horm. Behav. 54(4): 496-505.

Love, O.P., McGowan, P.O., and Sheriff, M.J. 2013. Maternal adversity and ecological stressors in natural populations: the role of stress axis programming in individuals, with implications for populations and communities. Funct. Ecol. 27(1): 81-92.

Lynn, S.E., and Kern, M.D. 2014. Environmentally relevant bouts of cooling stimulate corticosterone secretion in free-living eastern bluebird (Sialia sialis) nestlings: Potential 
links between maternal behavior and corticosterone exposure in offspring. Gen. Comp. Endocrinol. 196: 1-7. doi:http://dx.doi.org/10.1016/j.ygcen.2013.11.011.

Madliger, C.L., and Love, O.P. 2016. Conservation implications of a lack of relationship between baseline glucocorticoids and fitness in a wild passerine. Ecol. Appl. 26(8): $2732-2745$.

Maziarz, M., Broughton, R.K., and Wesołowski, T. 2017. Microclimate in tree cavities and nestboxes: implications for hole-nesting birds. For. Ecol. Manag. 389: 306-313.

Merila, J., Kruuk, L., and Sheldon, B. 2001. Natural selection on the genetical component of variance in body condition in a wild bird population. J. Evol. Biol. 14(6): 918-929. doi:10.1046/j.1420-9101.2001.00353.x.

Montgomery, D.C., Peck, E.A., and Vining, G.G. 2012. Introduction to linear regression (5 ${ }^{\text {th }}$ ed.). John Wiley \& Sons, Inc., Hoboken, N.J.

Monticelli, D., and Ramos, J.A. 2012. Laying date, body mass and tick infestation of nestling tropical Roseate Terns Sterna dougallii predict fledging success, first-year survival and age at first return to the natal colony. Ibis, 154(4): 825-837. doi:10.1111/j.1474919X.2012.01271.x.

Moreira, F., Beja, P., Morgado, R., Reino, L., Gordinho, L., Delgado, A., and Borralho, R. 2005. Effects of field management and landscape context on grassland wintering birds in southern Portugal. Agric. Ecosyst. Environ. 109(1-2), 59-74. 
Mundry, R. 2011. Issues in information theory-based statistical inference-a commentary from a frequentist's perspective. Behav. Ecol. Sociobiol. 65(1): 57-58.

Murtaugh, P.A. 2009. Performance of several variable-selection methods applied to real ecological data. Ecol. Lett. 12(10): 1061-1068.

Musgrove, A.B., and Wiebe, K.L. 2014. Northern Flickers increase provisioning rates to raise more but poorer quality offspring when given experimentally enlarged broods. Auk, 131(4): 571-582. doi:10.1642/AUK-14-51.1.

Naef-Daenzer, B., Widmer, F., and Nuber, M. 2001. Differential post-fledging survival of great and coal tits in relation to their condition and fledging date. J. Anim. Ecol. 70(5): 730738. doi:10.1046/j.0021-8790.2001.00533.x.

Nakagawa, S., and Schielzeth, H. 2013. A general and simple method for obtaining $R^{2}$ from generalized linear mixed-effects models. Methods Ecol. Evol. 4(2): 133-142.

Nilsson, J., and Svensson, M. 1996. Sibling competition affects nestling growth strategies in marsh tits. J. Anim. Ecol. 65(6): 825-836. doi:10.2307/5680.

Nord, A., and Nilsson, J. 2011. Incubation temperature affects growth and energy metabolism in blue tit nestlings. Am. Nat. 178(5): 639-651. doi: 10.1086/662172.

Peig, J., and Green, A.J. 2009. New perspectives for estimating body condition from mass/length data: the scaled mass index as an alternative method. Oikos, 118(12): 1883-1891. doi: 10.1111/j.1600-0706.2009.17643.x. 
Pérez, J.H., Ardia, D.R., Chad, E.K., and Clotfelter, E.D. 2008. Experimental heating reveals nest temperature affects nestling condition in tree swallows (Tachycineta bicolor). Biol. Lett. 4(5): 468-471.

Rensel, M.A., Wilcoxen, T.E., and Schoech, S.J. 2010. The influence of nest attendance and provisioning on nestling stress physiology in the Florida scrub-jay. Horm. Behav. 57(2): 162-168. doi: 10.1016/j.yhbeh.2009.10.009.

Rivers, J.W., Liebl, A.L., Owen, J.C., Martin, L.B., and Betts, M.G. 2012. Baseline corticosterone is positively related to juvenile survival in a migrant passerine bird. Funct. Ecol. 26(5): 1127-1134.

Robinson, T.J., Siefferman, L. Bentz, A.B., and Risch, T.S. 2014. The separate effects of egg size and parental quality on the development of ornamental plumage coloration. Ibis, 156(2): 415-423. doi:10.1111/ibi.12143.

Romero, L.M., and Fairhurst, G.D. 2016. Measuring corticosterone in feathers: Strengths, limitations, and suggestions for the future. Comp. Biochem. Physiol. A 202: 112-122.

Ros, A. 1999. Effects of testosterone on growth, plumage pigmentation, and mortality in blackheaded gull chicks. Ibis, 141(3): 451-459. doi:10.1111/j.1474-919X.1999.tb04414.x.

Saino, N., Romano, M., Ferrari, R., Martinelli, R., and Moller, A. 2005. Stressed mothers lay eggs with high corticosterone levels which produce low-quality offspring. J. Exp. Zool. 303(11): 998-1006. doi:10.1002/jez.a.224. 
Salaberria, C., Celis, P., Lopez-Rull, I., and Gil, D. 2014. Effects of temperature and nest heat exposure on nestling growth, dehydration and survival in a Mediterranean hole-nesting passerine. Ibis, 156(2): 265-275. doi:10.1111/ibi.12121.

Sankamethawee, W., Gale, G.A., and Hardesty, B.D. 2009. Post-fledgling survival of the cooperatively breeding puff-throated bulbul (Alophoixus pallidus). Condor, 111(4): 675683. doi:10.1525/cond.2009.090006.

Sasvari, L., Peczely, P., and Hegyi, Z. 2004. The influence of parental age and weather on testosterone concentration and offspring survival in broods of tawny owl Strix aluco. Behav. Ecol. Sociobiol. 56(3): 306-313. doi:10.1007/s00265-004-0788-3.

Schwabl, H. 1996. Environment modifies the testosterone levels of a female bird and its eggs. J. Exp. Zool. 276(2): 157-163. doi:10.1002/(SICI)1097-010X(19961001)276:2<157::AIDJEZ9>3.0.CO;2-N.

Shutler, D., Mullie, A., and Clark, R.G. 2004. Tree swallow reproductive investment, stress, and parasites. Can. J. Zool. 82(3): 442-448.

Sicurella, B., Caffi, M., Caprioli, M., Rubolini, D., Saino, N., and Ambrosini, R. 2015. Weather conditions, brood size and hatching order affect common swift Apus apus nestlings' survival and growth. Bird Study, 62(1): 64-77. doi:10.1080/00063657.2014.989193.

Siikamaki, P. 1996. Nestling growth and mortality of pied flycatchers Ficedula hypoleuca in relation to weather and breeding effort. Ibis, 138(3): 471-478. doi:10.1111/j.1474919X.1996.tb08067.x. 
Spencer, K.A., Evans, N.P., and Monaghan, P. 2009. Postnatal stress in birds: a novel model of glucocorticoid programming of the hypothalamic-pituitary-adrenal axis. Endocrinology, 150(4): 1931-1934.

Stodola, K.W., Linder, E.T., Buehler, D.A., Franzreb, K.E., Kim, D.H., and Cooper, R.J. 2010. Relative influence of male and female care in determining nestling mass in a migratory songbird. J. Avian Biol. 41(5): 515-522. doi: 10.1111/j.1600-048X.2009.04751.x.

Szöllősi, E., Rosivall, B., Hasselquist, D., and Török, J. 2009. The effect of parental quality and malaria infection on nestling performance in the collared flycatcher (Ficedula albicollis). J. Ornithol. 150(3): 519-527. doi:10.1007/s10336-008-0370-2.

Trivers, R.L. 1974. Parent-offspring conflict. Am. Zool. 14: 249-264.

Visser, M., Holleman, L., and Gienapp, P. 2006. Shifts in caterpillar biomass phenology due to climate change and its impact on the breeding biology of an insectivorous bird. Oecologia, 147(1): 164-172. doi:10.1007/s00442-005-0299-6.

Voltura, K.M., Schwagmeyer, P.L., and Mock, D.W. 2002. Parental feeding rates in the house sparrow, Passer domesticus: are larger-badged males better fathers? Ethology, 108(11): 1011-1022. doi: 10.1046/j.1439-0310.2002.00831.x.

Wayland, M., Gilchrist, H., Marchant, T., Keating, J., and Smits, J. 2002. Immune function, stress response, and body condition in arctic-breeding common eiders in relation to cadmium, mercury, and selenium concentrations. Environ. Res. 90(1): 47-60. doi:10.1006/enrs.2002.4384. 
Wiebe, K.L. 2001. Microclimate of tree cavity nests: is it important for reproductive success in northern flickers? Auk, 118(2): 412-421. doi:http://dx.doi.org/10.1642/00048038(2001)118[0412:MOTCNI]2.0.CO.

Wiggins, D.A. 1989. Heritability of body size in cross-fostered tree swallow broods. Evolution, 43(8): 1808-1811.

Wiggins, D.A. 1990. Food availability, growth, and heritability of body size in nestling tree swallows (Tachycineta bicolor). Can. J. Zool. 68(6): 1292-1296.

Wilson, A.J., and Nussey, D.H. 2010. What is individual quality? An evolutionary perspective. Trends Ecol. Evol. 25(4): 207-214.

Winkler, D.W., Luo, M.K., and Rakhimberdiev, E. 2013. Temperature effects on food supply and chick mortality in tree swallows (Tachycineta bicolor). Oecologia, 173(1): 129-138. 
Table 1. Mean and standard error (SE) for all parameters in the global models for $\mathrm{CORT}_{\mathrm{f}}$ and morphology of nestling tree swallows (Tachycineta bicolor) at the St. Denis National Research Area, Saskatchewan, 2013 and 2014. Sample size $(n)$ is given for each model and indicates the number of nestlings.

\begin{tabular}{|c|c|c|c|c|}
\hline Model & $n$ & Parameter & Mean & SE \\
\hline $\mathrm{CORT}_{\mathrm{f}}$ & 88 & $\begin{array}{l}\text { year } \\
\text { hatching date } \\
\text { brood size } \\
\text { nestling body mass at day } 12 \\
\text { box type of hatching (aspen vs. plywood) } \\
\text { box type of rearing (aspen vs. plywood) } \\
\text { manipulation (foster vs. non-foster nestling) }\end{array}$ & $\begin{array}{c}\cdot \\
167.64 \text { (June 17) } \\
6.68 \\
23.99 \\
\cdot \\
\cdot \\
.\end{array}$ & $\begin{array}{c}\cdot \\
0.58 \\
0.11 \\
0.18 \\
\cdot \\
.\end{array}$ \\
\hline Morphology & 502 & $\begin{array}{l}\text { year } \\
\text { hatching date } \\
\text { brood size } \\
\text { natal female body mass } \\
\text { foster female body mass } \\
\text { natal female wing length } \\
\text { foster female wing length } \\
\text { natal female head-bill length } \\
\text { foster female head-bill length } \\
\text { box type of rearing (aspen vs. plywood) } \\
\text { box type of hatching (aspen vs. plywood) } \\
\text { manipulation (foster vs. non-foster nestling) }\end{array}$ & $\begin{array}{c}\text {. } \\
167.33 \text { (June 16) } \\
6.42 \\
21.72 \\
21.73 \\
115.83 \\
115.75 \\
28.81 \\
28.79 \\
. \\
.\end{array}$ & $\begin{array}{c}. \\
0.19 \\
0.04 \\
0.05 \\
0.05 \\
0.14 \\
0.14 \\
0.04 \\
0.04 \\
. \\
.\end{array}$ \\
\hline
\end{tabular}


Table 2. Results of general linear mixed effects models testing for effects of cross-fostering manipulations on feather corticosterone $\left(\mathrm{CORT}_{\mathrm{f}}\right)$ and morphology of nestling Tree Swallows (Tachycineta bicolor) at the St. Denis National Research Area, Saskatchewan in 2013 and 2014.

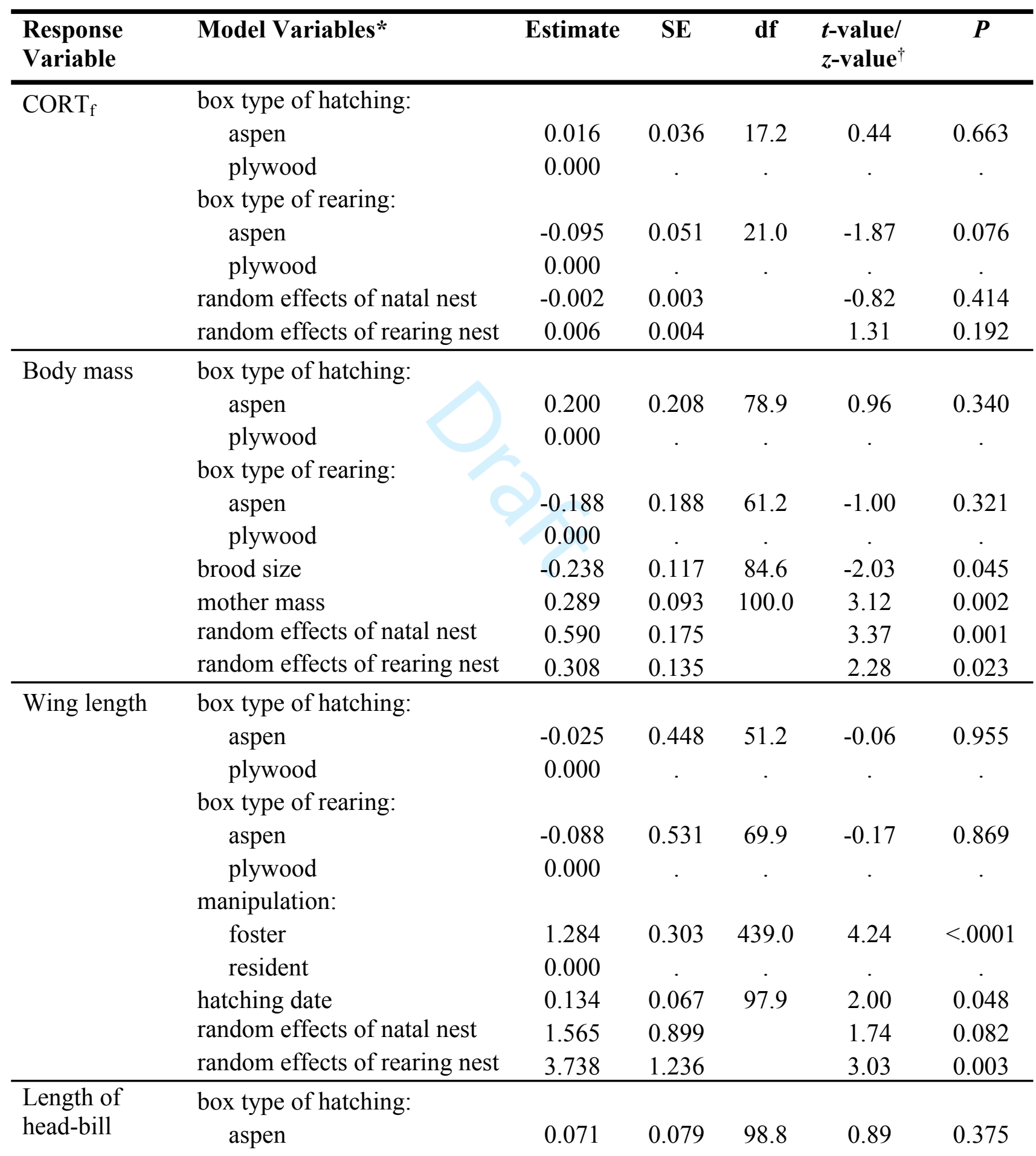


plywood

box type of rearing:

aspen
plywood
manipulation:
foster
resident
random effects of natal nest
random effects of rearing nest

0.000

$-0.036$

0.000

0.105

0.049

447.0

2.12

0.035

0.000

0.089

0.024

3.77

$<0.001$

0.003

0.013

0.25

0.799

*In models, "box type of hatching" and "box type of rearing" were the nest box types (either thicker-walled aspen or thinner-walled plywood) that the nestling was hatched and reared in, respectively, "manipulation" was whether or not the nestling was cross-fostered, and "random effects of natal and rearing nest" referred to the nest identities of where the nestling originated from and where it was raised, respectively.

$\dagger t$-values and $z$-values are given for fixed and random effects, respectively. 
Figure 1. Mean feather corticosterone $( \pm \mathrm{SE} ; \mathrm{pg} / \mathrm{mm})$ and sample size $(n)$ for nestling Tree Swallows (Tachycineta bicolor) that were hatched in either aspen (grey) or plywood (white) nest boxes, then raised in either the same nest box ("resident") or in a different nest box ("foster"). The different nest box could either be the same nest box type as the nestling's natal box type (i.e., aspen to aspen or plywood to plywood nest box) or different (i.e., aspen to plywood nest box or vice versa). Nestlings raised in plywood boxes had higher feather corticosterone than nestlings raised in aspen boxes. 


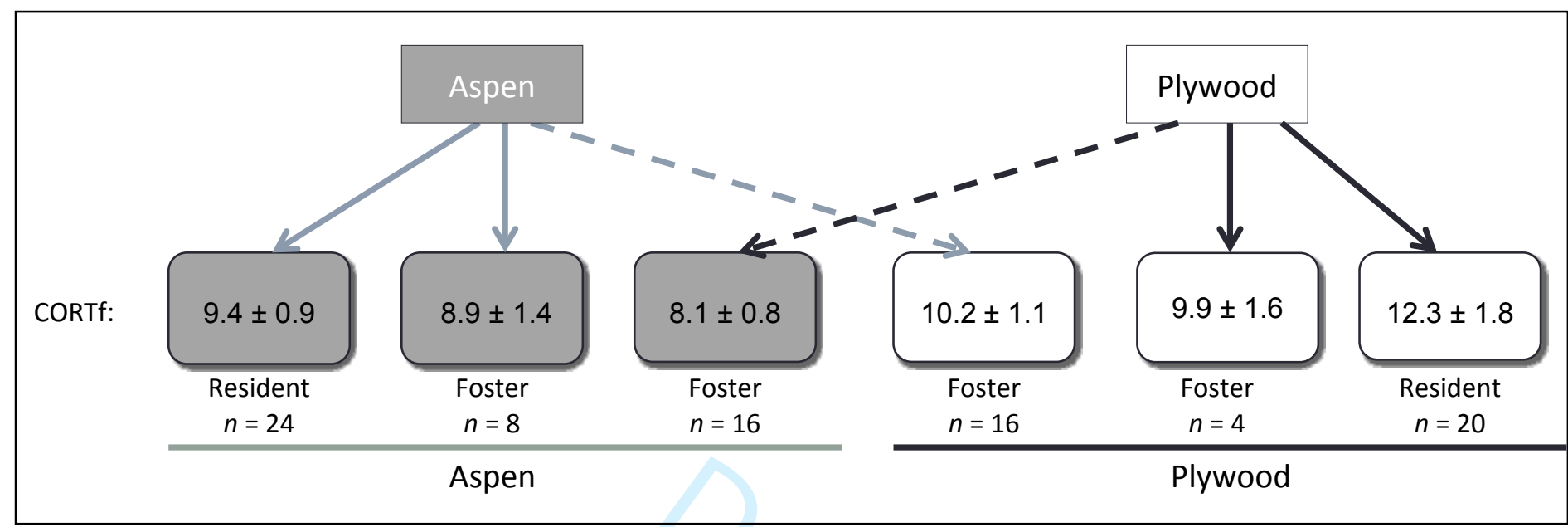

